\title{
OS EVENTOS E A HIERARQUIA DAS NECESSIDADES HUMANAS DE MASLOW: CONJECTURAS NA SOCIEDADE CONTEMPORÂNEA
}

Luciane Terumi Matsuoka, Jerson Joaquim da Silva

FATEC - Faculdade de Tecnologia - Centro Paula Souza / Curso: Tecnologia em Eventos, Presidente Prudente / SP. Email: luciane_prudente@yahoo.com.br

\section{RESUMO}

O presente trabalho, fruto de pesquisas iniciadas e concluídas no primeiro semestre deste ano, tem como embasamento, a análise do conceito e múltiplos significados dos eventos na sociedade contemporânea, correlacionando os mesmos com a Hierarquia das Necessidades Humanas de Maslow, buscando enfatizar, esmiuçar e levar à reflexão sobre as mudanças sociais e comportamentais ocorridas, sobretudo, nas últimas décadas.Tais mudanças fizeram com que os eventos deixassem de possuir características majoritariamente comemorativas ou de entrosamento social, devido à abrangência das mídias e à globalização, que não foram aspectos, apenas econômico ou tecnológico, mas que afetaram, significativamente, o modo como se edificam as relações humanas. Através de pesquisas bibliográficas ou observações empíricas, ficou clara a mutabilidade ocorrida na área de eventos, bem como a necessidade premente de maiores estudos e reflexões sobre o assunto.

Palavras-chave: eventos, Hierarquia das Necessidades Humanas de Maslow, globalização, mídias, entrosamento social.

\section{INTRODUÇÃO}

Ao analisarmos o conceito de evento como sendo um acontecimento programado, que atende a finalidades específicas, podemos então deduzir que seu planejamento é por diversas vezes meticulosamente preparado, para que não apenas cumpra os objetivos pelos quais foi pensado, mas também para que direcione o imaginário dos convidados ou telespectadores para conjunturas específicas.

Nesse cenário, podemos perceber que múltiplas emoções envolvem, sobretudo, os anfitriões, como a ansiedade para que tudo transcorra conforme o planejado no decorrer do evento, despertando com isso nervosismo, alegrias e medos. Além do desejo, mesmo que inconsciente ou não de exibir um status social superior, ou mesmo capacidades individuais que queirammostrar aos demais.

Essas emoções e contextos podem ser analisados sob a ótica da teoria da Hierarquia das Necessidades Humanas de Maslow, ocasionando, com isso, uma ampliação no modo como podemos entender quais são as reais motivações que envolvem o planejamento e a execução dos mesmos. 


\section{OBJETIVO}

O intento profícuo do presente trabalho é correlacionar os eventos, desde seu planejamento à sua execução, com aHierarquia das Necessidades Humanas de Maslow na sociedade contemporânea.

\section{METODOLOGIA}

Pesquisas bibliográficas, utilização de editores eletrônicos de texto e figura.

\section{RESULTADOS}

Os eventos fazem parte do cotidiano da maior parte da sociedade contemporânea, estando intrínsecos às nossas raízes culturais e sociais. Valorizam-se em escala global, anseiam por novas emergências e criam novas necessidades humanas, supervalorizadas, principalmente, pela mídia, que propagandeia um consumismo desenfreado, em que os eventos convertem-se em mercadorias passíveis, portanto, de serem adquiridas como bens que podem ser exibidos como símbolo de status social.

Para melhor ilustrar esse panorama, tomemos como exemplo as festividades que acompanham a cerimônia de casamento. Esse evento, talvez um dos mais importantes na vida de muitos casais, possui múltiplos significados, repletos de fantasias, sonhos, ansiedades, desejos, entre outros. Converte-se facilmente na oportunidade profícua de emitir mensagens acerca dos anfitriões da festa, muitas vezes supervalorizadas em relação ao caráter comemorativo e religioso que o evento poderia ter a princípio.

O jornal Folha de São Paulo, (edição de31 de março de 2013), define bem esse cenário, intitulada "Contra atrasos das noivas, padres vetam casamento noturno: padre da Igreja Matriz de Batatais-SP, diz que casais estavam mais interessados em status". Em entrevista à uma repórter, o padre P. B. fez a seguinte explanação: "as noivas se atrasam muito e passaram a usar o casamento como um evento social - não religioso. Agora, para casar à noite só se for às sextas-feiras. Aos sábados, vão até as $17 \mathrm{~h}$. O meu ideal, enquanto padre é salvar almas e não apenas satisfazer o ego de noivos".

Ainda segundo o pároco, as pessoas estariam procurando esse local específico, pela "beleza do prédio e não pelo interesse sacramental".

No entanto, se intentarmos esmiuçar os múltiplos significados que os eventos podem assumir, nos deparamos com tantas possibilidades de estudo que poderíamos incorrer no erro de 
objetivar traçar um panorama deveras geral e, portanto, inespecífico demais a respeito do tema. $\mathrm{E}$ foi justamente por esse motivo que objetivamos correlacionar os eventos à teoria da Hierarquia das Necessidades de Maslow.

Abraham Maslow (01/04/08 - 08/06/70) foi um psicólogo norte americano, criador da teoria da Hierarquia das Necessidades de Maslow, na qual pretendia demonstrar que o comportamento motivacional humano pode ser explicado por determinadas necessidades humanas, dispostas em níveis hierárquicos.

Silva (2012 apud CHIAVENATO, 2000), na obra em que trabalha com a questão da motivação nas relações de trabalho, utilizou a seguinte citação, que elucida bem o que Maslow desejava ao criar sua hierarquia:

Abraham Maslow apresentou uma teoria da motivação segundo a qual as necessidades humanas estão organizadas e dispostas em níveis, numa hierarquia de importância e influência e que pode ser visualizada como uma pirâmide. Na base da pirâmide estão as necessidades mais baixas (necessidades fisiológicas) e no topo, as necessidades mais elevadas (autorealização). CHIAVENATO (2000, p. 253)

De maneira imagética a Pirâmide de Maslow, estaria representada da seguinte maneira:

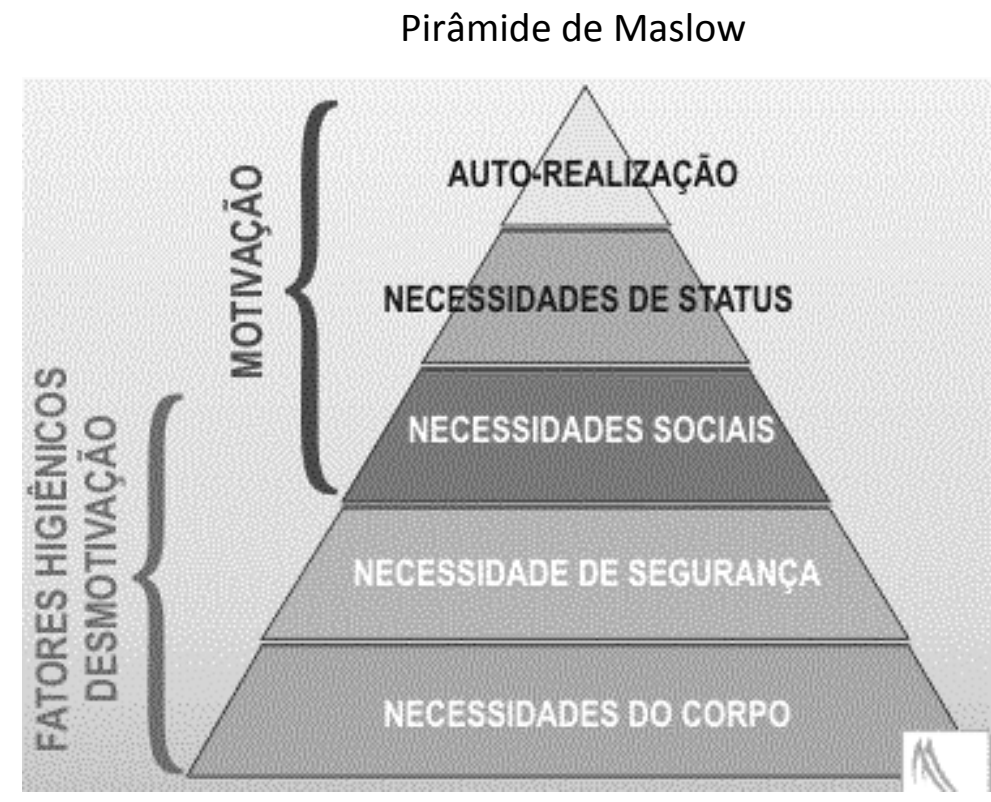

Fonte: Chiavenato (2000, p.254). 
As necessidades de Maslow podem ser melhor elucidadas do seguinte modo:

1 - Necessidades do corpo: seriam as necessidades mais básicas, mais elementares, instintivas e vitais dos seres humanos, tais como: respiração, comida, água, sexo, sono, excreção. Precisam ser satisfeitas para que possamos nos preocupar com outras tarefas.

2 - Necessidades de segurança: surgem quando as necessidades primárias (necessidades do corpo) estão relativamente satisfeitas. Dizem respeito à busca de proteção contra ameaças ou privações. Está presente no mundo contemporâneo, não somente devido aos crescentes índices de criminalidade, mas também devido ao estrondoso alarde propagandeado pelas mídias televisivas, jornalísticas e virtuais, que exploram de modo pungente as notícias e histórias que envolvem atos violentos e exploratórios de grande repercussão.

3 - Necessidades sociais: surgem quando as necessidades do corpo e de segurança encontram-se relativamente satisfeitas. Relacionam-se com sentimentos humanos presentes na maior parte das pessoas, como a necessidade de amar e pertencer a um determinado grupo ou núcleo familiar. Fazem parte dessas necessidades, a troca de amizade, afeição, companheirismo e aceitação social. Quando não adequadamente satisfeitas, podem contribuir na criação de indivíduos hostis em relação às pessoas que os cercam.

4 - Necessidades de status: correspondem ao modo como os indivíduos se avaliam e percebem a si próprios. Fazem parte dessas necessidades, a autoapreciação, autoconfiança, necessidade de status, de aprovação social, autonomia, independência, prestígio e confiança.

5-Auto realização: são as necessidades mais elevadas, correspondendo à realização do próprio potencial, num circuito contínuo de autodesenvolvimento.

Segundo Kondo, as necessidades humanas não ascenderiam nessa hierarquia numa sequência ordenada, ou seja, as cinco necessidades estariam sempre presentes, mas variariam em importância relativa, gradativamente, de um nível mais baixo para outro mais elevado, conforme o padrão de vida dos indivíduos se elevasse.

Se levarmos em consideração que a teoria motivacional de Maslow aqui apresentada, é aplicável a quaisquer esferas da vida comportamental humana, tendo sido precursora inclusive de outras teorias, como a de Herzerberg, que estudou a relação da motivação no ambiente de trabalho, podemos correlacionar a teoria de Maslow com os eventos sob uma ótica bastante interessante, podendo ser melhor elucidada do seguinte modo: 
1 - Muitas vezes, as pessoas que desejam realizar um grande evento, não economizando recursos financeiros para tal, muitas vezes querem mostrar a seus convidados que foram capazes de "vencer na vida", estando agora num patamar econômico e social mais elevado. Realizando a correlação desse cenário com a Teoria de Maslow, poderíamos afirmar que esses indivíduos querem mostrar aos demais que foram capazes de ascender as hierarquias básicas - Necessidades Fisiológicas e Necessidades de Segurança, estando agora preocupados e desejosos de trabalhar os aspectos inerentes mais às outras hierarquias - Necessidades Sociais, Necessidades de Status e Auto Realização.

2 - Esses desejos, emoções, e até mesmo necessidades de status e pertença que envolvem as relações sociais, não apenas num evento, mas em todos os outros aspectos da vida humana, possuem raízes muito mais profundas, relacionadas com as grandes transformações globais que tivemos sobretudo nas últimas décadas, causando prejuízos no modo como percebemos a vida em sociedade, como podemos observar na seguinte afirmação:

A competitividade, sugerida pela produção e pelo consumo, é a fonte de novos totalitarismos, mais facilmente aceitos graças à confusão dos espíritos que se instala. Tem as mesmas origens a produção, na base mesma da vida social, de uma violência estrutural, facilmente visível nas formas de agir dos Estados, das empresas e dos indivíduos. A perversidade sistêmica é um dos seus corolários. Dentro desse quadro, as pessoas sentem-se desamparadas, o que também constitui uma incitação a que adotem, em seus comportamentos ordinários, práticas que alguns decênios atrás eram moralmente condenadas. Há um verdadeiro retrocesso quanto á noção de bem público e de solidariedade. (SANTOS 2012, p.37)

3 - Se as relações sociais que envolvem os eventos podem ser relacionadas com a Hierarquia das Necessidades Humanas de Maslow, temos, portanto, um leque bastante abrangente de possibilidades de estudo, de múltiplos enfoques e espectros, essenciais não apenas para indivíduos mais críticos, mas também para os profissionais ligados à área de organização de eventos.

\section{DISCUSSÃO}

As emoções, as necessidades e, sobretudo, os desejos, são aspectos tão inerentes aos seres humanos que espelham-se em suas ações, no modo como agem, planejam, sentem. No entanto, as mesmas fazem parte de um processo contínuo, por vezes repleto de dificuldades e obstáculos, 
e contribuir na formação de um indivíduo saudável sendo quase sempre algo complicado, repleto de peculiaridades:

Podemos considerar o processo de crescimento sadio como uma série interminável de livre escolha, com que cada indivíduo se defronta a todo o instante, ao longo da vida, quando deve escolher entre os prazeres da segurança e do crescimento, dependência e independência, regressão e progressão, imaturidade e maturidade. A segurança tem suas angústias e seus prazeres; o crescimento tem suas angústias e seus prazeres." (MASLOW 1970, p.74)

$E$, como os eventos evolvem enfaticamente um espectro deveras amplo de emoções, por serem ações previamente planejadas que também obedecem a uma lógica organizacional, sendo muito distantes de serem algo mecanicista, são momentos simbólicos, carregados de emoções, que podem ser analisadas segundo outros enfoques e até mesmo teorias.

\section{CONCLUSÃO}

Correlacionar a área de eventos com a Hierarquia das Necessidades Humanas de Maslow foi algo a princípio dificultoso. As pesquisas, iniciadas e concluídas no primeiro semestre deste ano, nos instigavam ainda mais, justamente pela quase ausência de bibliografias específicas. Faltavam referências bibliográficas congruentes com as duas áreas em questão, que unissem um assunto ao outro. No entanto, ao invés de encararmos esse obstáculo como o princípio do fim, optamos por principiar um novo enfoque, uma nova possibilidade de estudo, majoritariamente na área de eventos, que só nos últimos anos passou a ter maiores investimentos, com a abertura de cursos tecnológicos específicos. Longe de encerrarmos a discussão, nosso maior anseio é suscitar outras questões que possam vir a enriquecer e contribuir na consolidação de uma sociedade mais crítica.

Para encerrarmos, registramos como considerações finais algo bastante simples, ou seja, é possível analisarmos o contexto que envolve os eventos sob a ótica da teoria de Maslow, justamente pelos mesmos envolverem um amplo espectro de emoções humanas, que são historicamente, socialmente e economicamente mutáveis.

\section{REFERÊNCIAS}

CHIAVENATO, Idalberto. Introdução à Teoria Geral da Administração; edição compacta; 2a ed. revista e atualizada. Rio de Janeiro: Campus, 2000. 
KONDO, Yoshio. Motivação Humana: Um Fator-Chave para o Gerenciamento; tradução Dario I. Miyake; revisão técnica Afonso C. C. Fleury. 3a ed. São Paulo.Editora Gente, 1997.

MASLOW, Abrahan. Introdução à Psicologia do Ser. Rio de Janeiro: Livraria Eldorado, 1970.

MASLOW, Abrahan. Introdução à Psicologia do Ser. Rio de Janeiro: Livraria Eldorado, 1970.

SANTOS, Milton, Por uma outra globalização: do pensamento único à consciência universal. Rio de Janeiro: Record, 2012.

TESTA, Fernanda. "Contra atrasos das noivas, padres vetam casamento noturno: padre da Igreja Matriz de Batatais, diz que casais estavam mais interessados em status". Jornal Folha de São Paulo, 31 de março, 2013. 